09

\title{
О природе свечения полиметилметакрилата при возбуждении пучком электронов субнаносекундной и наносекундной длительностей
}

\author{
(C) В.И. Олешко, ${ }^{1}$ Е.Х. Бакшт, ${ }^{2}$ А.Г. Бураченко, ${ }^{2,3}$ В.Ф. Тарасенко ${ }^{1,2,3}$ \\ ${ }^{1}$ Национальный исследовательский Томский политехнический университет, \\ 634050 Томск, Россия \\ ${ }^{2}$ Институт сильноточной электроники СО РАН, \\ 634055 Томск, Россия \\ ${ }^{3}$ Национальный исследовательский Томский государственный университет, \\ 634050 Томск, Россия \\ e-mail:VFT@loi.hcei.tsc.ru
}

(Поступило в Редакцию 19 апреля 2016 г.)

\begin{abstract}
Представлены результаты исследований физической природы свечений, возникающих в полиметилметакрилате при возбуждении пучками электронов субнаносекундной и наносекундной длительности. Изучены пространственные, амплитудные и спектрально-кинетические характеристики свечения при варьировании плотности энергии электронного пучка в диапазоне от $10^{-4}$ до $4 \cdot 10^{-1} \mathrm{~J} / \mathrm{cm}^{2}$. Установлено, что при низкой плотности энергии электронного пучка основным видом свечения является катодолюминесценция образца. С увеличением плотности энергии наносекундного электронного пучка, или (и) числа импульсов возбуждения электронным пучком субнаносекундной длительности, в зоне облучения происходит электрический пробой полиметилметакрилата, который сопровождается вспышкой свечения плотной низкотемпературной плазмы.
\end{abstract}

DOI: 10.21883/JTF.2017.02.44137.1860

\section{Введение}

Пучки электронов нано- и субнаносекундной длительностей широко используются в импульсной спектрометрии для диагностики природных и искусственных кристаллов [1-3], исследования свойств энергетических материалов $[4,5]$ и светодиодных наногетероструктур [6,7]. При сравнительно малых плотностях энергии электронного пучка $(H)$ наносекундной длительности, как правило, регистрируется спонтанная катодолюминесценция возбужденных образцов, а при увеличении $H$ в полупроводниковых кристаллах высокого качества наблюдается стимулированное излучение [7]. Дальнейшее увеличение $H$ приводит к разрушению образцов вследствие накопления инжектированного в диэлектрик отрицательного объемного заряда электронного пучка и последующего электрического пробоя $[7,8]$.

В последние годы повысился интерес к исследованию излучения кристаллов и полиметилметакрилата (ПММА) под действием электронных пучков. Различные кристаллы, в том числе из алмаза, начали широко применять для диагностики потока убегающих электронов в установках типа ТОКАМАК [9-11], используя излучение Вавилова-Черенкова (ИВЧ). В работе [12] была предпринята попытка применить для регистрации ИВЧ полиметилметакрилат. Для возбуждения ПММА использовался ускоритель с газовым диодом, заполненным воздухом атмосферного давления. Из [12] следовало, что основной вклад в свечение образца давало ИВЧ, а интенсивность катодолюминесценции была малой и не превышала 25\% от интенсивности ИВЧ. Однако данный вывод был сделан без проведения измерений спектров излучения ПММА, а также спектра электронного пучка.

Цель настоящей работы - выяснить физическую природу свечений, возникающих в ПММА при возбуждении пучком электронов субнаносекундной и наносекундной длительностей. Электронные пучки формировались в импульсных ускорителях электронов с газовым и вакуумным диодами. Плотности энергии пучка электронов $(H)$ в экспериментах варьировали от $10^{-4}$ до $0.4 \mathrm{~J} / \mathrm{cm}^{2}$, а длительности импульса тока пучка на полувысоте составляли $0.1-0.6$ и $12 \mathrm{~ns}$.

\section{Экспериментальная аппаратура и методика}

Эксперименты были проведены на двух установках с генератором СЛЭП-150М [13], к которому подключался газовый диод (установка № 1) и с генератором ГИН-600 [14], к которому подключался вакуумный диод (установка № 2).

СЛЭП-150М формировал импульсы напряжения в передающей линии с амплитудой в падающей волне $\sim 150 \mathrm{kV}$ и длительностью на полувысоте $1 \mathrm{~ns}$. Длительность фронта импульса напряжения составляла $\sim 250 \mathrm{ps}$ на уровне 0.1-0.9. Исследования были проведены с трубчатым катодом из нержавеющей стали. Катод имел форму трубки диаметром $6 \mathrm{~mm}$ с толщиной стенки $200 \mu \mathrm{m}$, торец которой был округлен. Амплитуда сверх- 
короткого лавинного электронного пучка (СЛЭП) после анодной фольги или число электронов в пучке определялись с помощью конусного коллектора с диаметром приемной части $20 \mathrm{~mm}$. Временное разрешение данного коллектора составляло $\sim 80$ ps. Энергия электронов определялась по ослаблению тока СЛЭП в фильтрах из алюминиевой фольги различной толщины [15]. Для изменения амплитуды и плотности тока пучка и его длительности давление в газовом диоде, который заполнялся гелием, варьировало от 3 до 760 Torr. Это позволило изменять плотность тока пучка от единиц до сотен ампер на квадратный сантиметр. Наибольшие амплитуды СЛЭП были получены в гелии при давлении 30 Torr. Длительность импульса СЛЭП при уменьшении давления гелия от 760 до 9 Torr изменялась от 100 до 600 ps. Максимальные плотности энергии электронного пучка с генератором СЛЭП-150М составляли $\sim 0.01 \mathrm{~J} / \mathrm{cm}^{2}$, минимальные, при которых удавалось регистрировать осциллограммы СЛЭП, были на три порядка меньше.

Излучение ПММА регистрировалось фотодиодом PD025 (катод LNS20 компании Photek, время нарастания переходной характеристики $\sim 80 \mathrm{ps}$ ). Импульсы с фотодиода, коллектора и емкостных делителей подавались на осциллограф DSO-X6004A (6 GHz, 20 выборок за наносекунду). Спектры излучения ПММА измерялись с помощью спектрометра Ocean Optics HR2000+ES (диапазон 190-1100 nm, спектральное разрешение $\sim 0.9 \mathrm{~nm}$ ). Спектральные и амплитудно-временные характеристики излучения на первой установке были исследованы для трех пластинок из ПММА толщиной 0.9, 6 и $10 \mathrm{~mm}$.

Генератор ГИН-600 [14] формировал на разрядном промежутке импульс напряжения с максимальной амплитудой $\sim 350 \mathrm{kV}$. Длительность импульса тока сильноточного электронного пучка (СЭП) на полувысоте составляла $12 \mathrm{~ns}$, диапазон варьируемой плотности энергии $\sim 0.01-0.4 \mathrm{~J} / \mathrm{cm}^{2}$.

Использовались два метода регистрации спектров свечения ПММА: „спектр по точкам“ и „спектр за импульс“. Первый метод позволял регистрировать спектры свечения с помощью импульсного спектрометра на основе дифракционного монохроматора МДР-23, ФЭУ-84 и осциллографа Tektronix DPO 3034, связанного с компьютером. Временное разрешение спектрометра составляло $\sim 15 \mathrm{~ns}$. Во втором методе спектры свечения регистрировались с помощью оптоволоконного спектрометра AvaSpec-2048 (диапазон 340-900 nm, спектральное разрешение $\sim 3 \mathrm{~nm})$. Пространственное распределение свечения по поверхности образца фотографировалось зеркальной цифровой фотокамерой SONY DSLR-A500 за один импульс возбуждения через микроскоп МБС-10. Морфологию остаточных разрушений регистрировали микровизором проходящего света $\mu$ Vizo-101. Количество импульсов возбуждения варьировало от 1 до 100. Измерения проводились при температуре $300 \mathrm{~K}$.

\section{Результаты и обсуждение}

\section{Основные закономерности свечения и разрушения ПММА при возбуждении слЭП}

При возбуждении пучком электронов на первой установке всех трех пластинок из ПММА наблюдалось голубоватое свечение, интенсивность которого возрастала с ростом амплитуды и длительности импульса тока СЛЭП. Однако интенсивность свечения всех пластинок при атмосферном давлении гелия в газовом диоде была очень мала и не регистрировалась фотодиодом. На рис. 1 показаны импульсы тока пучка и излучения ПММА при длительности импульса тока пучка на полувысоте $0.25 \mathrm{~ns}$.

Из приведенных осциллограмм следует, что длительность импульса излучения ПММА существенно превышает длительность импульса тока пучка и составляет $\sim 1.5 \mathrm{~ns}$ на полувысоте. Этот факт свидетельствует о том, что данное излучение не является ИВЧ, а связано с импульсной катодолюминесценцией (ИКЛ) ПММА. Спектры излучения и пропускания ПММА, приведенные на рис. 2, также подтверждают этот вывод. Действи-
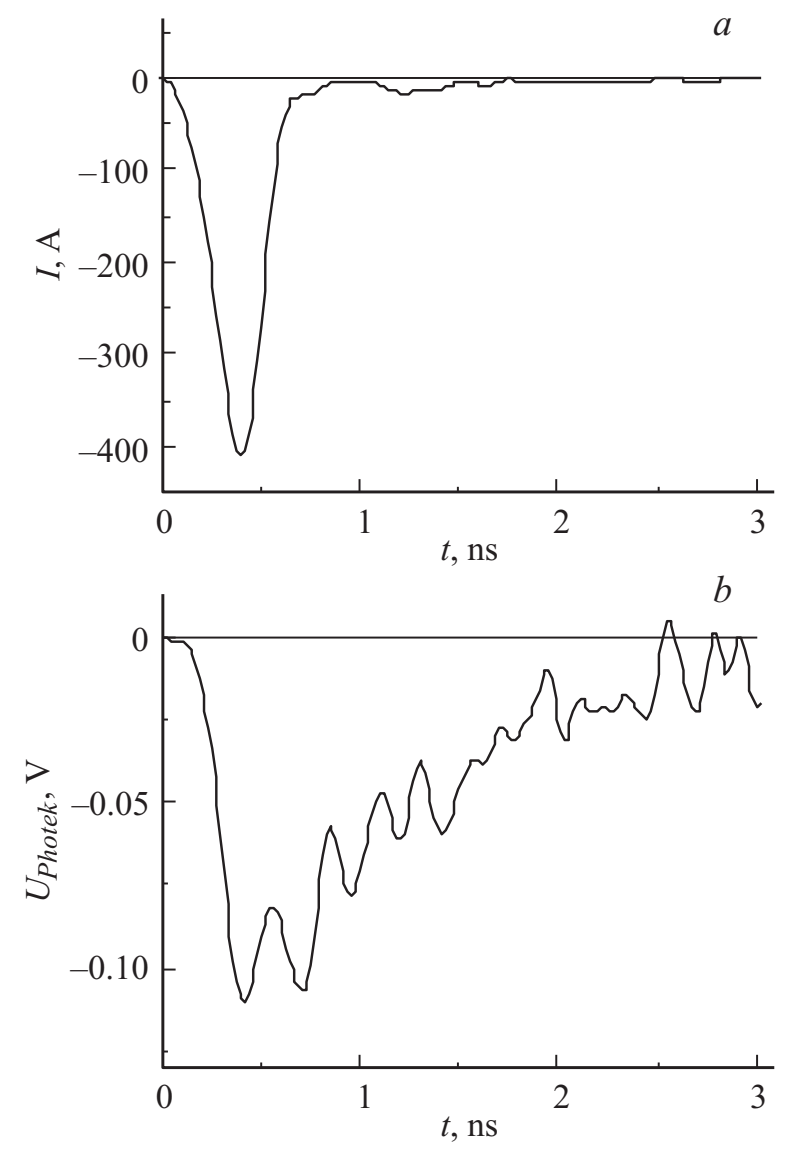

Рис. 1. Импульс тока пучка убегающих электронов $(a)$ и осциллограмма импульса излучения образца из ПММА толщиной $6 \mathrm{~mm}(b)$ при давлении гелия в газовом диоде 30 Torr. Межэлектродный зазор в газовом диоде $d=14 \mathrm{~mm}$. Полоса пропускания осциллографа $6 \mathrm{GHz}$. 


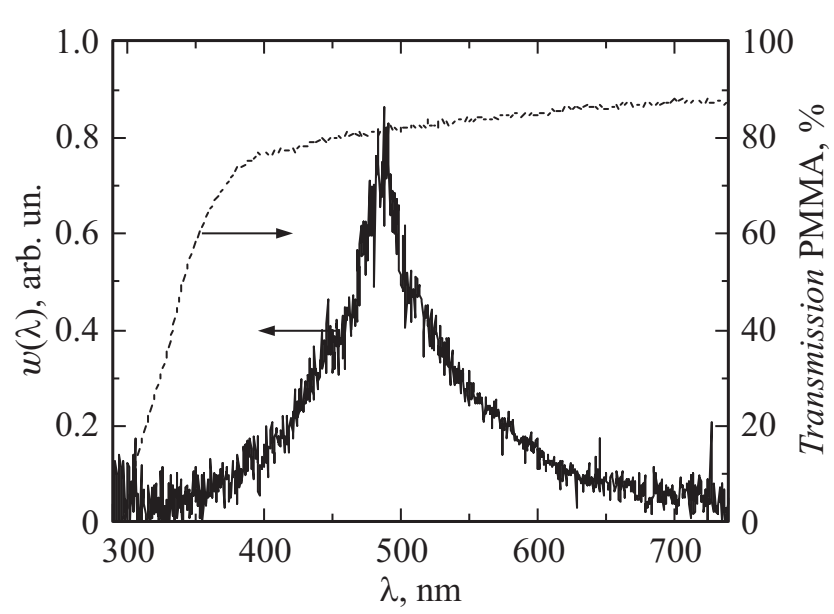

Рис. 2. Спектр излучения (сплошная) и пропускания (пунктир) ПММА.

тельно, на спектрограмме излучения видна одна полоса с максимумом на длине волны $490 \mathrm{~nm}$. Как известно [16], интенсивность ИВЧ должна увеличиваться в области прозрачности ПММА с уменьшением длины волны. Однако на регистрируемых спектрах интенсивность излучения уменьшается в области короче $490 \mathrm{~nm}$ с уменьшением длины волны.
На рис. 3 приведены фотографии свечения ПММА при максимальных плотностях тока пучка в первых импульсах возбуждения $(a)$, а также после 100 и более импульсов возбуждения $(b)$.

Анализ фотографий, приведенных на рис. 3, свидетельствует о том, что в первых импульсах возбуждения и максимальных плотностях тока пучка $\left(H \sim 0.01 \mathrm{~J} / \mathrm{cm}^{2}\right)$, а также при малых плотностях тока СЛЭП $\left(H \leq 0.001 \mathrm{~J} / \mathrm{cm}^{2}\right)$ наблюдается сравнительно равномерная по облучаемой поверхности катодолюминесценция образцов. Наблюдаемые неоднородности на рис. 3, $a$ связаны с флуктуациями плотности тока пучка в отдельных импульсах. Увеличение числа импульсов облучения при $H \sim 0.01 \mathrm{~J} / \mathrm{cm}^{2}$ привело к накоплению инжектированного в образец отрицательного объемного заряда СЛЭП и инициированию электрического пробоя ПММА в зоне торможения электронного пучка. Электрический пробой реализуется в виде стримерных разрядов (СР), которые инициируются на возбуждаемой поверхности образца и развиваются в область локализации отрицательного объемного заряда, пространственное распределение которого определяется энергетическим спектром СЛЭП. Электрические разряды регистрируются как по свечению плотной низкотемпературной плазмы, образующейся в каналах электрического пробоя (КЭП), так и по морфологии остаточных
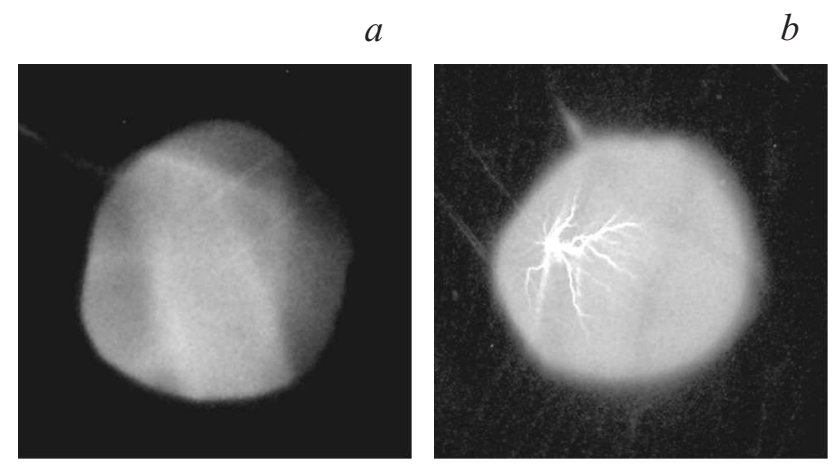

$b$

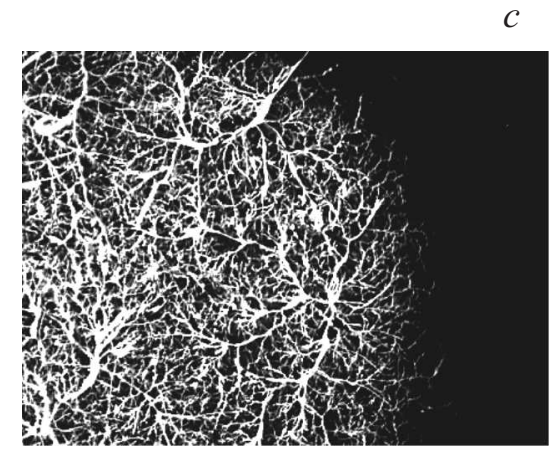

Рис. 3. Фотографии свечения ПММА за один импульс $(a, b)$ и морфология остаточных разрушений $(c)$, образующихся в зоне торможения СЛЭП в результате развития электрического пробоя. Диаметр светящейся области $(a, b)$ и зоны разрушения, изображение которой увеличено, $(c) \sim 6 \mathrm{~mm}$. Количество импульсов облучения - 500 при частоте $1 \mathrm{~Hz}(c)$.

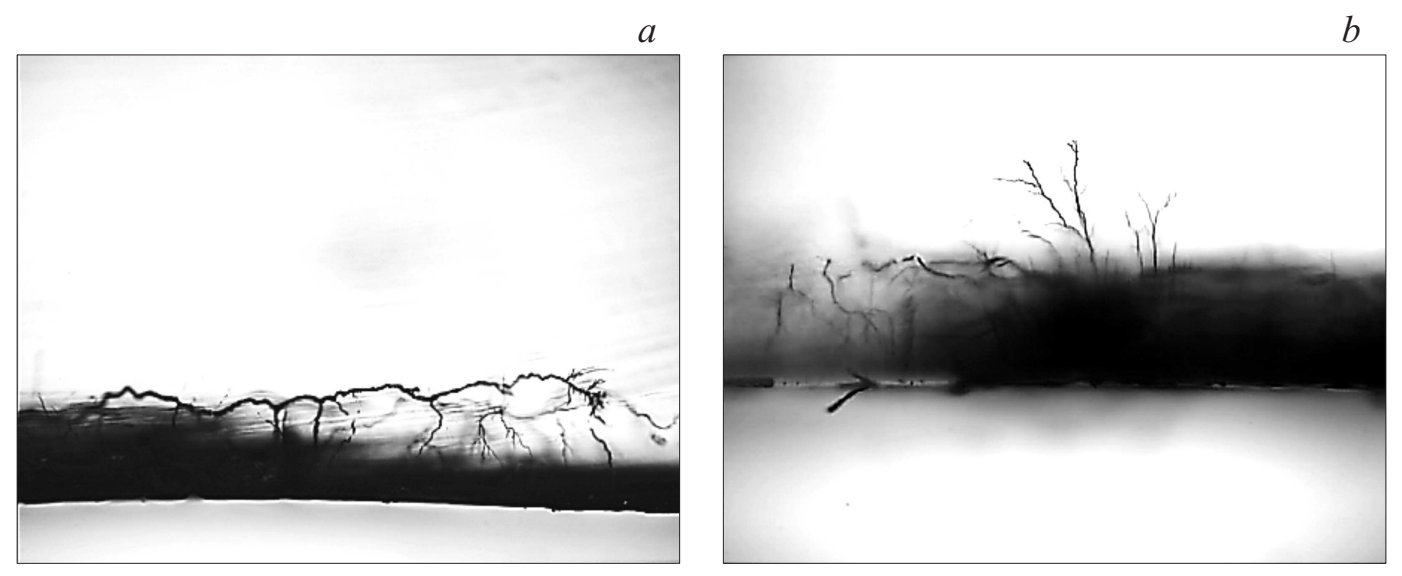

Рис. 4. Пространственное распределение КЭП вдоль направления распространения СЛЭП, $a$ - на расстоянии $4 \mathrm{~mm}$ от оси пучка, $b-$ на оси пучка. Размеры поля фотографии $1467 \times 1970 \mu \mathrm{m} . H \sim 0.01 \mathrm{~J} / \mathrm{cm}^{2}$. 


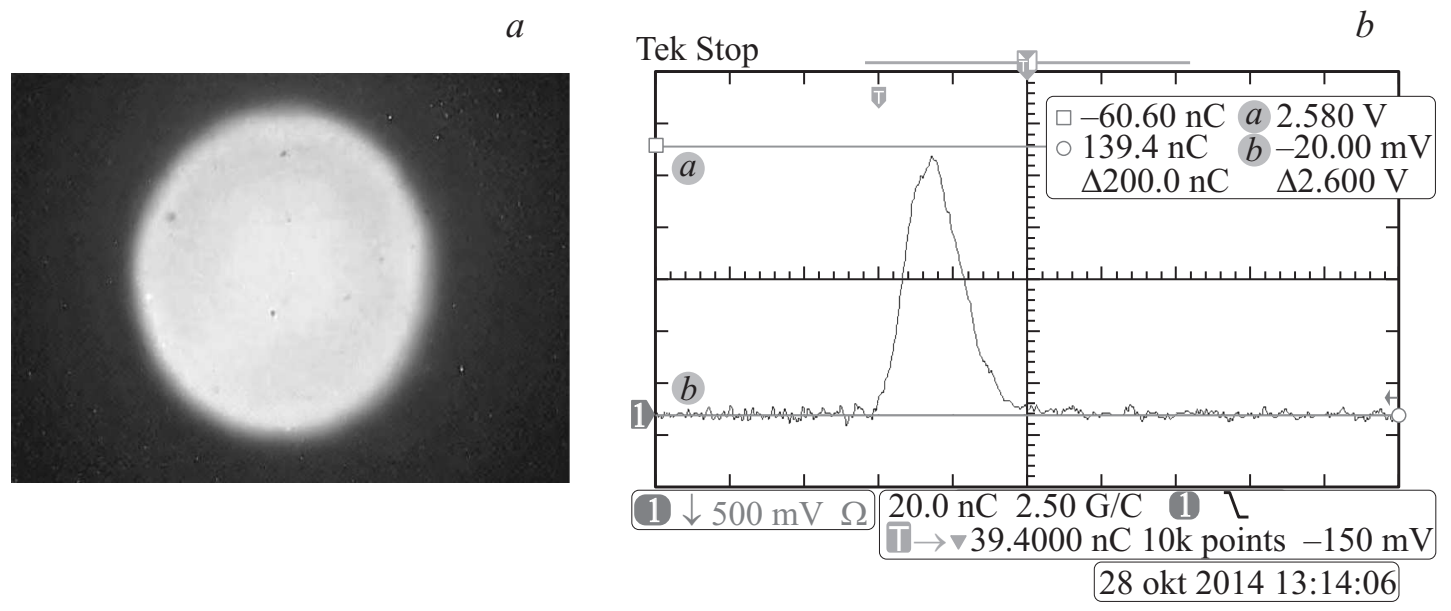

DPO3034 - 13:44:27 28.10.2014

Рис. 5. Фотография $(a)$ и осциллограмма $(b)$ катодолюминесценции ПММА. $H=0.1 \mathrm{~J} / \mathrm{cm}^{2}$.
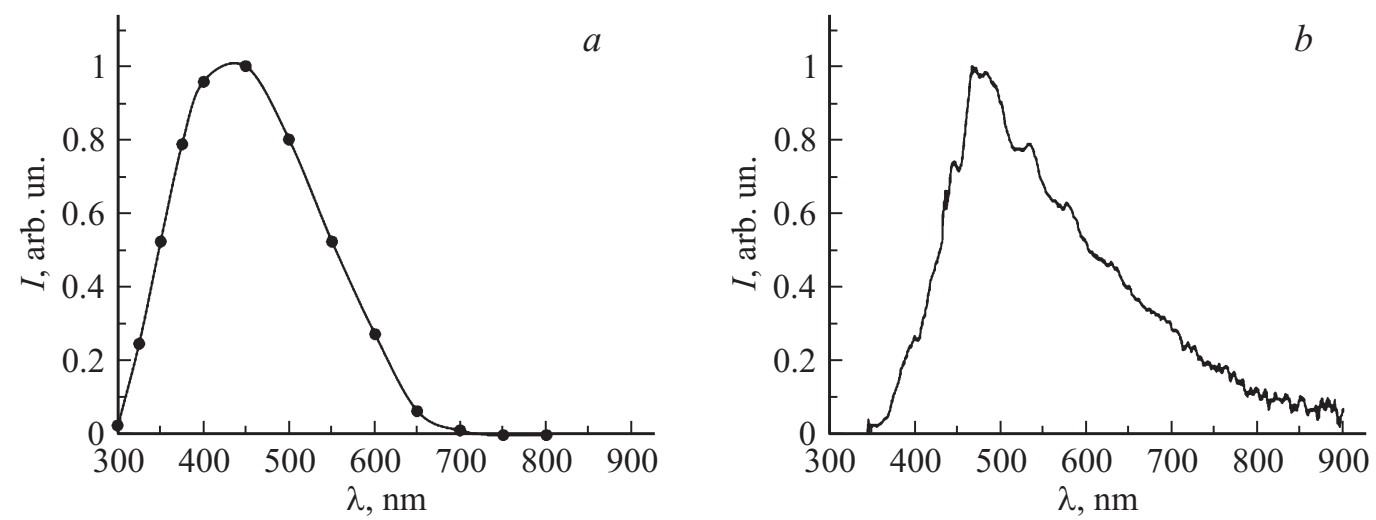

Рис. 6. Спектры ИКЛ $(a)$ и свечения плазмы СР $(b)$ в ПММА при облучении СЭП.

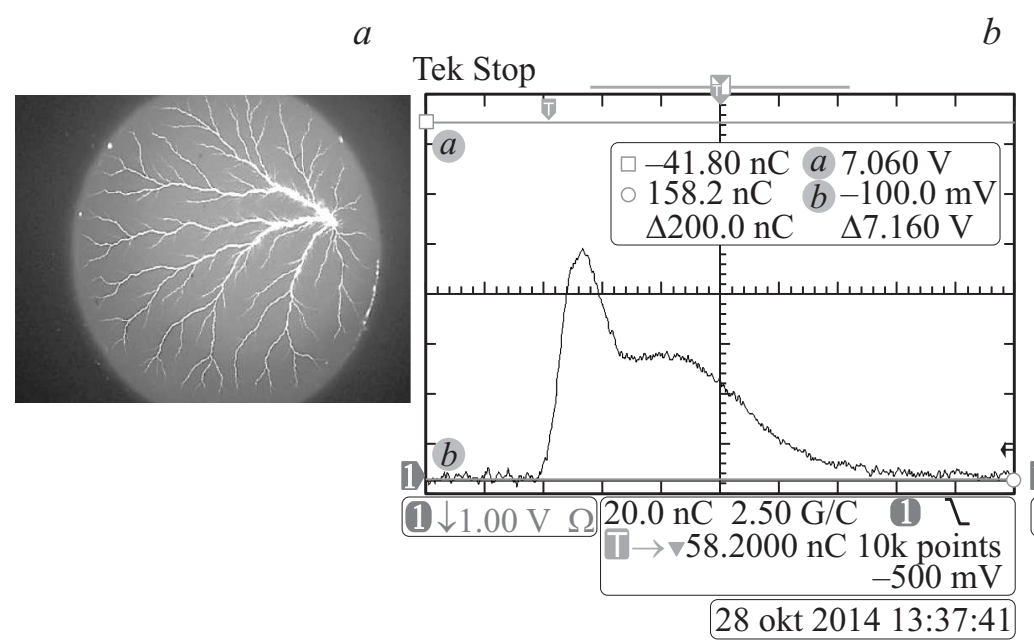

DPO3034 - 14:07:58 28.10.2014

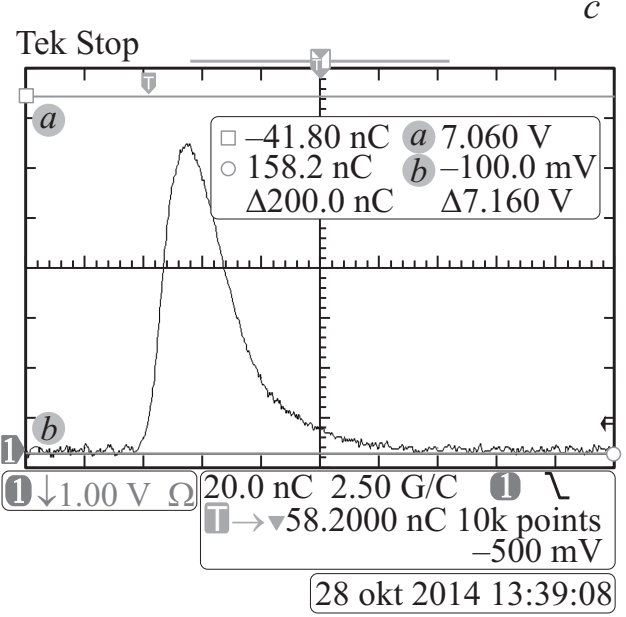

DPO3034 - 14:09:25 28.10.2014

Рис. 7. Фотография и осциллограммы свечения ПММА: $a, b-$ первый импульс возбуждения, $c-$ второй импульс возбуждения. Диаметр зоны облучения $5 \mathrm{~mm} . H=0.2 \mathrm{~J} / \mathrm{cm}^{2}$. 
разрушений рис. $3, b, c$. Длительность свечения плазмы, образующейся в КЭП с помощью фотодиода PD025, нам зарегистрировать не удалось из-за малой интенсивности излучения СР по сравнению с интенсивностью ИКЛ. На рис. 4, $a, b$ показаны фотографии поперечных сечений образцов ПММА после многоимпульсного облучения.

Видно, что пространственное распределение КЭП вдоль пробега электронного пучка не однородно. На периферии зоны облучения максимальная глубина локализации СР составляет $\sim 360 \mu \mathrm{m}$, а в центральной зоне облучения $\sim 720 \mu \mathrm{m}$, что соответствует энергиям СЛЭП $\sim 200$ и $\sim 300 \mathrm{keV}$.

\section{Основные закономерности свечения и разрушения ПММА при возбуждении СЭП}

Спектральные и кинетические характеристики свечения, индуцированного СЭП в ПММА при различных плотностях энергии пучка, приведены на рис. 5-7. Установлено, что спектральные характеристики свечения зависят от $H$. При $H<0.2 \mathrm{~J} / \mathrm{cm}^{2}$ наблюдается ИКЛ образца (рис. 5, $a$ ), длительность которой на полувысоте (рис. $5, b)$ составляет $\sim 17 \mathrm{~ns}$ и сопоставимо с временным разрешением импульсного спектрометра.

Преобразование спектра ИКЛ в сплошной спектр излучения плазмы электрических разрядов (рис. 6) происходит при плотности энергии пучка $H^{*} \sim$ $\sim 0.2 \mathrm{~J} / \mathrm{cm}^{2}$, что соответствует порогу формирования СР и появлению остаточных КЭП в данном материале (рис. 7,8).

Спектр ИКЛ полиметилметакрилата измерялся при $H=0.1 \mathrm{~J} / \mathrm{cm}^{2}$ в режиме многоимпульсного облучения (спектр по точкам). Спектр излучения плазмы СР, индуцированных СЭП в ПММА (рис. 6,b), измерялся за один импульс возбуждения.

Изучение кинетики свечения СР в зоне торможения электронного пучка при $H=H^{*}$ позволило обнаружить задержку свечения СР относительно импульса катодолюминесценции в первом импульсе возбуждения СЭП (рис. $7, b$ ). Видно, что импульс свечения ПММА состоит из двух разделенных во времени пиков: импульса катодолюминесценции и импульса плазменного свечения

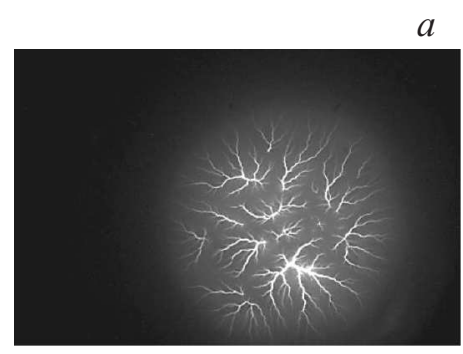

Pис. 8. Фотографии свечения возбуждаемой поверхности ПММА $(a)$ и пространственного распределения КЭП по глубине пробега электронного пучка $(b)$ после первого импульса СЭП. Диаметр зоны облучения $5 \mathrm{~mm} . H=0.4 \mathrm{~J} / \mathrm{cm}^{2}$. Размеры поля фотографии $(b) 784 \times 1054 \mu \mathrm{m}$.
СР. Задержка максимума второго пика относительно первого составляет $\sim 30 \mathrm{~ns}$ и связана с задержкой развития электрического пробоя относительно импульса возбуждения. Интенсивность свечения СР во втором импульсе облучения этой же зоны увеличивается более чем на порядок и представляет моноимпульс (рис. 7,c), причем задержка свечения СР относительно импульса катодолюминесценции отсутствует, что определяется развитием СР по сформированным в первом импульсе КЭП.

На рис. $8, a, b$ показаны фотографии свечения и пространственного распределения КЭП по глубине пробега электронного пучка в ПММА после однократного импульса облучения СЭП при $H=0.4 \mathrm{~J} / \mathrm{cm}^{2}$.

Видно, что с увеличением $H$ количество КЭП увеличивается. Распределение КЭП в зоне торможения электронного пучка близко к однородному, а максимальная глубина пробега достигает $\sim 650 \mu \mathrm{m}$, что соответствует средней энергии электронов в энергетическом спектре СЭП $290 \mathrm{keV}$.

\section{Заключение}

Анализ амплитудных и спектрально-кинетических характеристик излучения образцов ПММА при возбуждении СЛЭП малой плотности $\left(H \leq 0.001 \mathrm{~J} / \mathrm{cm}^{2}\right)$, а также характеристик свечения образцов в первых импульсах возбуждения при максимальных плотностях тока СЛЭП $\left(H \sim 0.01 \mathrm{~J} / \mathrm{cm}^{2}\right)$ свидетельствуют о том, что основной вклад в свечение ПММА дает катодолюминесценция. ИВЧ в условиях данного эксперимента зарегистрировано не было. Обнаружено, что многоимпульсное облучение ПММА СЛЭП, при $H \geq 0.01 \mathrm{~J} / \mathrm{cm}^{2}$ приводит к электрическому пробою образца вследствие накопления отрицательного объемного заряда электронного пучка и формирования в зоне торможения пучка сильного электрического поля. Электрические разряды регистрируются как по свечению плотной низкотемпературной плазмы, образующейся в каналах электрического пробоя, так и по морфологии остаточных разрушений. Измерить спектрально-кинетические характеристики стримерных разрядов в ПММА при возбуждении СЛЭП не удалось, так как интенсивность катодолюминесценции значительно превышает интенсивность излучения СР.

Возбуждение ПММА СЭП малой плотности $(H<$ $\left.<0.2 \mathrm{~J} / \mathrm{cm}^{2}\right)$ сопровождается импульсной катодолюминесценцией образца. При пороговой плотности энергии СЭП $H^{*} \sim 0.2 \mathrm{~J} / \mathrm{cm}^{2}$ в первом импульсе возбуждения образца на осциллограмме свечения регистрируются два сравнимых по амплитуде пика свечения: первый - безынерционный импульс катодолюминесценции, длительность которого не превышает временное разрешение импульсного спектрометра и второй - с задержкой $~ 30 \mathrm{~ns}$ импульс свечения плазмы, образующейся в каналах электрического пробоя (свечение стримерных разрядов). При $H>0.2 \mathrm{~J} / \mathrm{cm}^{2}$, как правило, наблюдается один пик 
свечения, связанный со свечением СР, интенсивность которых более, чем на порядок превышает интенсивность катодолюминесценции ПММА. Глубина проникновения СР в ПММА при их возбуждении пучком электронов субнаносекундной и наносекундной длительности коррелирует с энергией пучка электронов.

Исследование на установке № 1 было выполнено за счет гранта Российского научного фонда (проект № 14-29-00052).

\section{Список литературы}

[1] Lisitsyn V.M., Valiev D.T., Oleshko V.I. et al. // J. Luminescen. 2014. Vol. 153. P. 130-135.

[2] Морозова Н.К., Данилевич Н.Д., Олешко В.И., Вильчинская С.С. // Изв. вузов. Электроника. 2012. № 3. С. 3-10.

[3] Липатов Е.И., Лисицын В.М., Олешко В.И., Тарасенко В.Ф. // Изв. вузов. Физика. 2007. Т. 50. № 1. С. 53-57.

[4] Олешко В.И., Зарко В.Е., Лысык В.В. и др. // Письма в ЖТФ. 2015. Т. 41. Вып. 11. С. 10-15.

[5] Олешко В.И., Лисицын В.М., Скрипин А.С., Ципилев В.П. // Письма в ЖТФ. 2012. Т. 38. Вып. 9. С. 37-43.

[6] Олешко В.И., Горина С.Г., Корепанов В.И., Лисищын В.М. и др. // Изв. вузов. Физика. 2013. Т. 56. № 1. С. 55-58.

[7] Олешко В.И., Горина С.Г. // Письма в ЖТФ. 2015. Т. 41. Вып. 15. С. 75-82.

[8] Олешко В.И. Пороговые процессы в твердых телах при взаимодействии с сильноточными электронными пучками. Дис. докт. физ.-мат. наук. Томск, 2009. 317 с.

[9] Plyusnin V.V., Jakubowski L., Zebrowski J. et al. // Rev. Sci. Instrument. 2012. Vol. 83. N 8. P. 083505.

[10] Vorobev V.V., Tyukhtin A.V. // Phys. Rev. Lett. 2012. Vol. 108. N 18. P. 184801.

[11] Ginis V., Danckaert J., Veretennicoff I. et al. // Phys. Rev. Lett. 2014. Vol. 113. N 16. P. 167402.

[12] Babich L.P., Loiko T.V., Rodigin A.V. // IEEE Trans. Plasm. Sci. 2014. Vol. 42. N 4. C. $948-952$.

[13] Tarasenko V.F., Kostyrya I.D., Baksht E.K., Rybka D.V. // IEEE Trans. Dielect. Electric. Insulat. 2011. Vol. 18. N 4. P. $1250-1255$.

[14] Ковальчук Б.М., Месяи Г.А., Семин Б.М., Шпак В.Г. // Приборы и техника эксперимента. 1981. № 4. С. 15-18.

[15] Kozyrev A.V., Kozhevnikov V.Yu., Vorobyev M.S. et al. // Laser and Particle Beams. 2015. Vol. 33. P. 183-192.

[16] Jelly J.V. Cherenkov's Radiation and its Application. NY., USA: Pergamon, 1958. 